\title{
Properties of Ready Mixed Acrylic Paste for Exterior Insulation Using Pozzolanic Materials and Atomizing Slag
}

\author{
Sung-Yong Song, ${ }^{1}$ Hwa-Sung Ryu $\mathbb{D}^{2},{ }^{2}$ Sang-Heon Shin $\mathbb{D D}^{2}$ 'Deuck-Mo Kim, ${ }^{3}$ \\ and Won-Jun Park (iD ${ }^{4}$ \\ ${ }^{1}$ Yoosong Engineering, Dongan-gu 14054, Anyang, Republic of Korea \\ ${ }^{2}$ Hanyang Experiment and Consulting, Hanyang University, Ansan 15588, Republic of Korea \\ ${ }^{3}$ Hwarok Construction Industry, Hanyang University, Ansan 15588, Republic of Korea \\ ${ }^{4}$ Department of Architectural Engineering, Kangwon National University, Samcheok 25913, Republic of Korea
}

Correspondence should be addressed to Hwa-Sung Ryu; rhsung73@hanyang.ac.kr

Received 11 July 2018; Accepted 8 November 2018; Published 16 December 2018

Academic Editor: Antonio Boccaccio

Copyright (c) 2018 Sung-Yong Song et al. This is an open access article distributed under the Creative Commons Attribution License, which permits unrestricted use, distribution, and reproduction in any medium, provided the original work is properly cited.

\begin{abstract}
Ready mixed acrylic paste (RMAP) is a material used in exterior insulation systems of buildings; it consists of liquids and aggregates. However, it is considerably difficult to use an admixture to control the physical properties of the RMAP owing to problems associated with strength and workability. Thus, to improve the properties of RMAP, this study evaluates the properties of a mortar produced with RMAP as well as pozzolanic materials and atomizing slag, which is a by-product from the steelmaking industry. It was observed that if the density difference is large, a liquid RMAP may experience segregation. Through our experiments, we confirm that segregation resistance could be achieved even at $20 \%$ atomizing slag, which has a high density, by increasing the viscosity by approximately $1000 \mathrm{cP}$ through the use of $10 \%$ fly ash and $3 \%$ metakaolin in the RMAP. Despite the increase in viscosity with the addition of the atomizing slag, the flow of the RMAP increased from 160 to $175 \mathrm{~mm}$ due to the spherical particle shape of the slag; in addition, the strength and water absorption coefficient also improved. In particular, the adhesion tension increased from $1.8 \mathrm{~N} / \mathrm{mm}^{2}$ to $2.4 \mathrm{~N} / \mathrm{mm}^{2}$ or higher.
\end{abstract}

\section{Introduction}

Among the various methods to improve energy efficiency of buildings, window and wall insulation systems with high airtightness and insulation are typically applied. In particular, wall insulation systems are classified into interior insulation, exterior insulation, and hollow insulation systems; among these, the exterior insulation approach has several economic and workability advantages over the others. Furthermore, the exterior insulation method causes less heat bridging in structures, thus allowing for low-cost insulation renovation. The exterior insulation method involves attaching insulating materials using cement mortar to the exterior wall of masonry and reinforced concrete structures and leveling the surface, thus integrating the insulating materials within the structures themselves [1-5].
The cement mortar that is used as an adhesive in exterior insulation systems can be largely divided into dry mortar, which is then used by adding water at the construction site, and ready mixed acrylic paste (RMAP), which is cement mortar already mixed with aggregates, water, polymers, and additives [6-8]. The drawback of dry mortar is that the workability and strength of the obtained cement mortar vary considerably based on the amount of added water; in contrast, because RMAP already has the aggregates, water, and polymers mixed in, the workability can be predetermined, as the polymers are already dispersed in the cement mortar. However, a disadvantage of the RMAP is that it is difficult to use cement-based admixtures with it for performance improvement because RMAP with semiliquid is mixed with cement in the ratio of $1: 1$ in the construction field; thus, only aggregates, 
water, and polymers can be used in RMAP, and a separate admixture is difficult to use.

Admixtures are effective materials for dry shrinkage control, reduction of hydration heat, and improvement of packing density, among others; in particular, admixtures are divided into cement-based materials, which harden by directly reacting with water, and pozzolanic materials, which react with cement over time. Pozzolanic materials, including fly ash, metakaolin, and silica fumes, react with $\mathrm{Na}^{2+}, \mathrm{K}^{+}$, and $\mathrm{Ca}^{2+}$ in the cement, thus generating hydrates $[9,10]$. Hence, if there is no or a small number of reactive cations in the liquid when pozzolanic materials are applied to the RMAP, the pozzolanic material might not react, thus staying unreacted till later; therefore, applying pozzolanic materials to the RMAP might be effective in improving the physical characteristics of structures.

Furthermore, slags generated as industrial by-products in the steelmaking industry can lead to the problem of alkali leachate and fugitive dust if they are stored in an open storage yard. Therefore, to address this issue, the slags that are generated at high temperature are transformed into spherical particles of composite oxide, having a diameter of $4 \mathrm{~mm}$ or less, through an atomizing treatment. The slag produced through this process is called the "atomizing slag," which is a functional aggregate that suppresses the abnormal expansion inside cement by fixing free $\mathrm{CaO}$, effectively improving the fluidity of cement compounds. However, the application of atomizing slags is limited because they have high densities and pose a risk of segregation during longterm storage when used in the RMAP [11-13].

Therefore, in order to improve the physical and mechanical performance of RMAP, its properties were evaluated with the addition of pozzolanic materials and atomizing slags. First, pozzolanic materials, fly ash and metakaolin, are used to improve physical performance by improving the cement structure through the pozzolanic reaction. Then, atomizing slags are used to improve cement fluidity by replacing the aggregates in RMAP. To that end, aggregates of RMAP were produced by using pozzolanic materials and then stored in a sealed curing state at the temperature of $30^{\circ} \mathrm{C}$ for six months, after which the viscosity change in the cement was measured [14]. After mixing the pozzolanic materials and atomizing slags with the cement, the compressive strength analysis, flexural strength analysis, adhesion tension analysis, water absorption coefficient analysis, $\mathrm{X}$-ray diffraction (XRD), thermal analysis, and mercury instrusion porosimetry (MIP) were conducted. Furthermore, after replacing the aggregates in the RMAP with atomizing slags, segregation during storage, fluidity, compressive strength, flexural strength, and adhesion tension were analyzed.

\section{Experiment}

\subsection{Materials}

2.1.1. Pozzolanic Materials. Pozzolanic materials, fly ash and metakaolin, were used to improve the performance of the RMAP; their chemical compositions are listed in Table 1. In our study, the fly ash that was used had a density and fineness of $2.2 \mathrm{~g} / \mathrm{cm}^{3}$ and $2,800 \mathrm{~cm}^{2} / \mathrm{g}$, respectively, with the percentage of $\mathrm{SiO}_{2}+\mathrm{Al}_{2} \mathrm{O}_{3}+\mathrm{Fe}_{2} \mathrm{O}_{3}$ being approximately $78.346 \%$. Furthermore, the metakaolin used in our study had a density and Blaine value of $2.5 \mathrm{~g} / \mathrm{cm}^{3}$ and $120,000 \mathrm{~cm}^{3} / \mathrm{g}$, respectively.

2.1.2. Cement. The cement used for our mortar experiment was Class 1 ordinary Portland cement (OPC) whose chemical composition and physical properties are listed in Tables 2 and 3, respectively.

2.1.3. Fine Aggregates. For fine aggregates, quartz and atomizing slag were used in our study; their properties are listed in Table 4.

2.1.4. Polymers. The polymer used in our study was acrylic emulsion; its properties are listed in Table 5.

2.1.5. Methylcellulose. On contact with water, methylcellulose has the property of swelling up by absorbing the water. If a large quantity of methylcellulose is mixed with water, it rapidly absorbs water, transforming into a gel form, which causes the problem of low dispersibility. Thus, in this experiment, methylcellulose was dispersed in water slowly. The properties of methylcellulose are listed in Table 6.

2.1.6. $\mathrm{pH}$ Controller. To thicken the dispersed methylcellulose, 2-amino-2-methyl-1-propanol (hereinafter, AMP) was used as a $\mathrm{pH}$ controller; the properties of AMP are listed in Table 7. As mentioned above, when methylcellulose comes in contact with water, it swells and becomes highly viscous. If methylcellulose is not evenly dispersed, the swollen methylcellulose binds to undispersed methylcellulose and becomes vitrified. The delayed methylcellulose has been designed in such a manner that it does not swell immediately upon contact with water; however, its viscosity increases as the water temperature increases. Therefore, if a $\mathrm{pH}$ controller is used after methylcellulose is evenly dispersed, the $\mathrm{pH}$ increases to 9 or higher and methylcellulose swells rapidly, thus increasing the viscosity of the liquid.

\subsection{Experimental Procedure}

2.2.1. Overview. Table 8 lists the measurement method used for each part of our experiment. In our experiment, three types of characteristics were primarily evaluated; these characteristics can be summarized as follows:

(1) Stability of pozzolanic materials was evaluated using an analysis test of the cement paste with RMAP, but without fine aggregates

(2) Viscosity based on the mixing of pozzolanic materials and aggregates after production of RMAP

(3) Characteristics of the cement mortar with RMAP produced using aggregates and pozzolanic materials 
TABLE 1: Chemical composition of the pozzolanic materials.

\begin{tabular}{lcccccccccc}
\hline & $\mathrm{SiO}_{2}$ & $\mathrm{Al}_{2} \mathrm{O}_{3}$ & $\mathrm{CaO}$ & $\mathrm{MgO}$ & $\mathrm{SO}_{3}$ & $\mathrm{Fe}_{2} \mathrm{O}_{3}$ & $\mathrm{P}_{2} \mathrm{O}_{5}$ & $\mathrm{~K}_{2} \mathrm{O}$ & $\mathrm{Na}_{2} \mathrm{O}$ & $\mathrm{LOI}$ \\
\hline Fly ash & 50.88 & 22.33 & 6.702 & 2.18 & 0.795 & 5.136 & 0.237 & 0.98 & 1.69 & 9.07 \\
Metakaolin & 49.3 & 47.1 & 0.05 & 2.18 & 0.01 & 0.51 & 0.05 & 0.05 & 0.15 & 0.6 \\
\hline
\end{tabular}

TABle 2: Chemical composition of the OPC.

\begin{tabular}{cccccccccc}
\hline $\mathrm{SiO}_{2}$ & $\mathrm{Al}_{2} \mathrm{O}_{3}$ & $\mathrm{CaO}$ & $\mathrm{MgO}$ & $\mathrm{SO}_{3}$ & $\mathrm{Fe}_{2} \mathrm{O}_{3}$ & $\mathrm{P}_{2} \mathrm{O}_{5}$ & $\mathrm{~K}_{2} \mathrm{O}$ & $\mathrm{Na}_{2} \mathrm{O}$ & $\mathrm{LOI}$ \\
\hline 21.09 & 5.24 & 63.57 & 2.18 & 2.03 & 3.52 & 0.14 & 0.85 & 0.11 & 0.27 \\
\hline
\end{tabular}

TABle 3: Physical properties of the OPC.

\begin{tabular}{|c|c|c|c|c|c|c|}
\hline \multirow[t]{2}{*}{ Specific gravity $\left({ }^{\circ} \mathrm{C}\right)$} & \multirow[t]{2}{*}{ Blaine specific surface area $\left(\mathrm{cm}^{2} / \mathrm{g}\right)$} & \multicolumn{2}{|c|}{ Setting time $(\min )$} & \multicolumn{3}{|c|}{$\begin{array}{l}\text { Compressive strength of mortar } \\
(\mathrm{MPa})\end{array}$} \\
\hline & & Initial setting & Final setting & 3 days & 7 days & 28 days \\
\hline 3.15 & 3400 & 400 & 520 & 20 & 23 & 38 \\
\hline
\end{tabular}

TABle 4: Properties of the fine aggregates.

\begin{tabular}{lcccc}
\hline Type & Maximum size $(\mathrm{mm})$ & Unit weight $(\mathrm{kg} / \mathrm{l})$ & Specific gravity $\left(20^{\circ} \mathrm{C}\right)$ & Water absorption $(\%)$ \\
\hline Quartz & $0.14-0.3$ & 1.5 & 2.62 & 1.19 \\
Atomizing slag & $0.14-0.3$ & 2.2 & 3.56 & 0.42 \\
\hline
\end{tabular}

Table 5: Properties of the acrylic emulsion.

\begin{tabular}{lccc}
\hline Color & Solid content $(\%)$ & Viscosity $(\mathrm{mPa} \cdot \mathrm{s})$ & $\mathrm{pH}\left(20^{\circ} \mathrm{C}\right)$ \\
\hline White & 48 & 102 & 9.0 \\
\hline
\end{tabular}

TABLe 6: Properties of methylcellulose.

\begin{tabular}{lccc}
\hline Appearance & Particle size & Viscosity at $20^{\circ} \mathrm{C} 1 \%$ solution & Water content (\%) \\
\hline Whitish powder & $<600 \mu \mathrm{m}(98 \%)$ & $2,500-3,500 \mathrm{mPa} \cdot \mathrm{s}$ & Max $5 \%$ \\
\hline
\end{tabular}

TABLe 7: Properties of the $\mathrm{pH}$ controller (AMP) used in the experiment.

\begin{tabular}{lcccc}
\hline $\mathrm{pH}$ of $0.1 \mathrm{M}$ aqueous AMP solution & Molecular weight & Specific gravity at $25^{\circ} \mathrm{C}$ & Freezing point & $\mathrm{pKa}$ at $25^{\circ} \mathrm{C}$ \\
\hline 11.3 & 89.1 & 0.942 & $-2^{\circ} \mathrm{C}$ & 9.75 \\
\hline
\end{tabular}

TABLE 8: Measurement methods for different parts of the experiment.

\begin{tabular}{|c|c|c|c|}
\hline Part of the experiment & Sample & Measurement items & Standards \\
\hline \multirow{12}{*}{ RMAP with pozzolanic materials } & \multirow{3}{*}{ Cement paste } & $\mathrm{pH}$ & ASTM D1293-99 [15] \\
\hline & & XRD & ASTM D 1365-18 [16] \\
\hline & & TG-DTA & ASTM D 3850-12 [17] \\
\hline & \multirow{3}{*}{ RMAP } & Viscosity $(\mathrm{cP})$ & ASTM D 2196 [18] \\
\hline & & Segregation & ASTM C1610 [19] \\
\hline & & Viscosity $(\mathrm{cP})$ & ASTM D 2196 \\
\hline & \multirow{6}{*}{ Cement mortar } & Flow & ASTM C 230/230M-14 [20] \\
\hline & & Compressive strength & ASTM C 349 [21] \\
\hline & & Flexural strength & ASTM C 348 [22] \\
\hline & & Adhesion tension & ASTM D 7234-12 [23] \\
\hline & & Water absorption coefficient & ASTM C 1794-15 [24] \\
\hline & & MIP & ASTM D 3850-12 [25] \\
\hline
\end{tabular}


2.2.2. Semi Premix Mortar Using Pozzolanic Materials. The RMAP mixing method employed in our study is outlined as follows. First, water, polymers, and methylcellulose are evenly mixed together for $2 \mathrm{~min}$. Then, the $\mathrm{pH}$ controller is added to the mixture, and the viscosity of methylcellulose is increased by stirring the mixture. Then, the pozzolanic materials, quartz, and atomizing slags are added to the thickened mixture, which is further mixed for $2 \mathrm{~min}$ to produce RMAP. Figure 1 shows the flowchart of the RMAP mixing process.

2.2.3. Mixing Method Used for RMAP. Table 9 lists the composition of the paste and mortar used in our experiment. First, to evaluate their six-month stability, the paste and RMAP specimens were cured at a temperature of $30^{\circ} \mathrm{C}$ and relative density of $60 \%$ and then stored at $20^{\circ} \mathrm{C}$. Then, the polymer-cement mortar specimen was produced at a temperature of $20^{\circ} \mathrm{C}$.

In particular, the paste specimen was produced by mixing $100 \mathrm{~g}$ of OPC in the paste mixture for $3 \mathrm{~min}$; then, $\mathrm{pH}$ analysis, XRD, and TG-DTA (thermogravimetry-differential thermal analysis) were performed. For the measurement of the $\mathrm{pH}$ of the cement paste, $10 \mathrm{ml}$ of the mixture was collected and immersed in $100 \mathrm{~g}$ of distilled water, after which the $\mathrm{pH}$ was measured thrice: 2,4 , and 6 months after immersion. For XRD analysis, $30 \mathrm{~g}$ of the cured paste specimen was collected after 3 and 28 days and crushed to particles of $300 \mu \mathrm{m}$ or smaller sizes, or crushed and immersed in acetone and dried. Then, the specimen was analyzed using $\mathrm{Cu}$ radiation at $45 \mathrm{kV}$ and $40 \mathrm{~mA}$ using an X-ray diffractometer (Shimadzu XD-R1). The scanning rate was $5 \%$ min with a range of $5-60^{\circ}$.

The RMAP specimen was produced by mixing quartz and atomizing slags for $3 \mathrm{~min}$; then, the viscosity of the produced specimen was measured.

For the cement mortar, after cement was added to the RMAP, they were mixed for $3 \mathrm{~min}$. Then, the mixture was left standing for $2 \mathrm{~min}$ and mixed again for $2 \mathrm{~min}$ after then. The flow of the produced specimen was measured in accordance with ASTM C 230. The specimen of each mixture was poured in a $4 \mathrm{~cm} \times 4 \mathrm{~cm} \times 16 \mathrm{~cm}$ mold and stripped after curing for 18 hours. The compressive and flexural strengths were measured three times at 3, 7, and 28 days in accordance with ASTM C 348. In addition, the adhesion tension and water absorption coefficient were measured in accordance with ASTM D 7234-12 and ASTM C 1794-15, respectively.

\section{Results and Analysis}

\subsection{Storage Stability after Mixing Pozzolanic Admixture and Atomizing Slag}

3.1.1. Characteristics of the RMAP. Table 10 lists the $\mathrm{pH}$ and viscosity of RMAP. After mixing plain RMAP with fly ash and metakaolin, the $\mathrm{pH}$ of the RMAP increases sharply from 7 to 11 because of the addition of the $\mathrm{pH}$ controller. Though the $\mathrm{pH}$ of the specimen decreases slightly after fly ash is mixed into it, this $\mathrm{pH}$ change was not considerable. Furthermore, during the curing process, the $\mathrm{pH}$ hardly changed.
Thus, it can be deduced that there was almost no change in $\mathrm{pH}$ by the addition of fly ash and metakaolin. In the cement paste, fly ash and metakaolin react directly with $\mathrm{Ca}(\mathrm{OH})_{2}$ present in the cement to form hydrates, thus lowering the $\mathrm{pH}$; however, it is believed that, in the RMAP, the expected $\mathrm{pH}$ decrease because of this pozzolanic reaction was not observed because the chemical structure of AMP, which is used as a $\mathrm{pH}$ controller, raises the $\mathrm{pH}$ through the alcohol group at its terminal.

The viscosity of the semi premix paste after mixing and curing the RMAP for 6 months was approximately 743$860 \mathrm{cP}$. In particular, the viscosity of the plain specimen immediately after mixing was approximately $800 \mathrm{cP}$ but slightly increased to $830 \mathrm{cP}$ after curing for 6 months. In a similar manner, the viscosity of the specimen produced by mixing fly ash and metakaolin also slightly increased; it is considered that, after the dispersion process of methylcellulose, the undispersed methylcellulose absorbed water over time and diffused in the liquid, thus slightly increasing the viscosity of the mix.

When the changes in viscosity based on the mixing ratios of fly ash and metakaolin were examined, it was observed that the viscosity slightly decreased after the addition of fly ash and increased when metakaolin was added; it is considered that metakaolin increased the viscosity because it has a large specific surface area, thus requiring a large amount of water for fluidity.

3.1.2. XRD and TG-DTA of the RMAP. Figures 2 and 3 show the XRD graph for the RMAP according to the ages. It is observed that the XRD curves are similar with no significant differences between the semi premix paste immediately after mixing and the RMAP after curing for six months.

Figure 4 shows the TG-DTA graph of the RMAP mixed with cement. In this graph, the RMAP immediately after mixing and the semi premix paste after curing for six months show similar changes in the amount of calcium hydroxide. Table 11 lists the quantities of calcium hydroxide in the specimen by curing age; in particular, the amount of calcium hydroxide does not show a significant difference between the values immediately after mixing and curing the specimen for six months. This observation indicates that there was no pozzolanic reaction in the liquid during storage. Furthermore, the amount of calcium hydroxide in the specimen with metakaolin was lower than that in the one with fly ash; after 28 days, the amount of calcium hydroxide was approximately $65 \%$ that in the plain specimen.

3.1.3. Viscosity and Fluidity of Cement Mortar Based on Atomizing Slag Replacement Ratio. Table 12 lists the viscosity graph values for the RMAP based on the replacement ratio of atomizing slags. As the replacement ratio of the atomizing slag increased, the viscosity decreased and the fluidity increased. However, after six months, the specimen mixed with a high-density atomizing slag showed segregation. It is considered that the atomizing slag with coarse particles does not have a significant effect on the viscosity of the cement paste; however, the fluidity of the cement mortar 


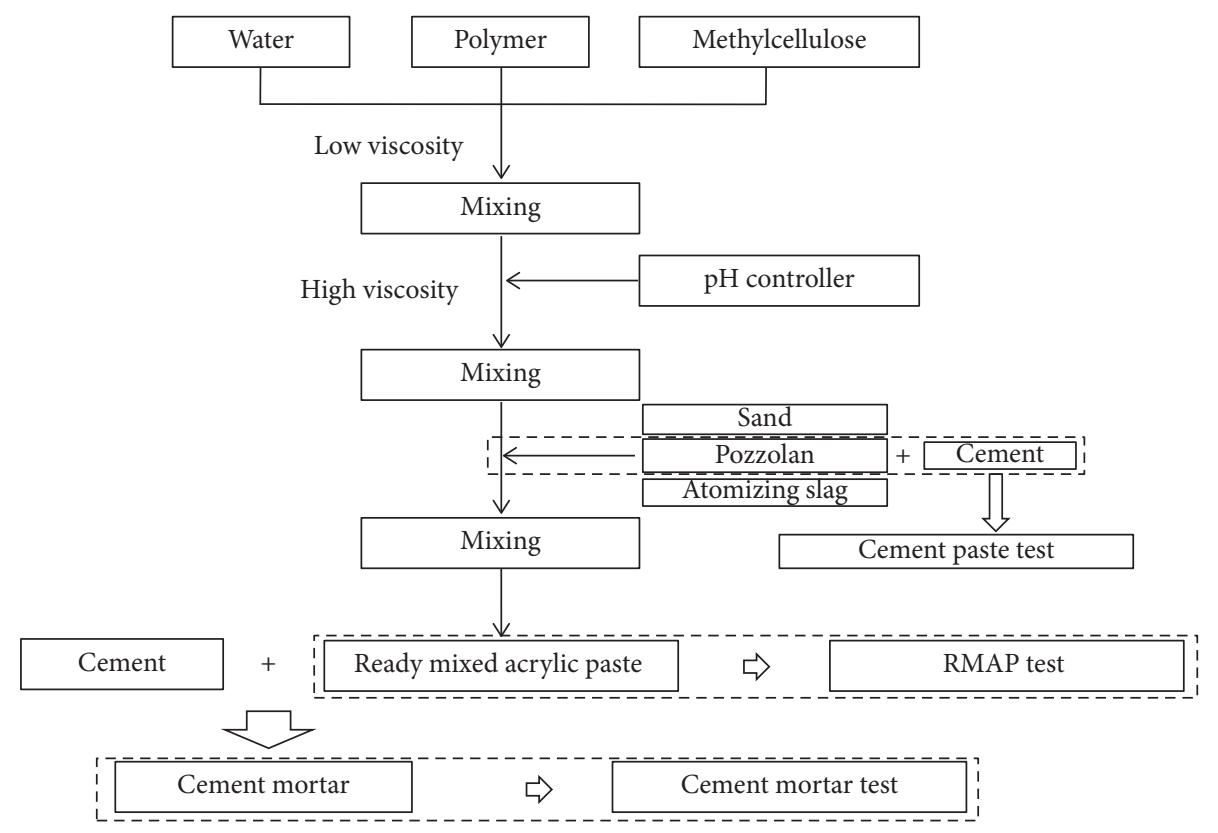

FIGURE 1: Flowchart of the RMAP mixing process.

TABle 9: Compositions of the paste and mortar.

\begin{tabular}{|c|c|c|c|c|c|c|c|c|c|}
\hline $\begin{array}{l}\text { Mixture } \\
\text { number }\end{array}$ & $\begin{array}{c}\text { Polymer } \\
\text { (g) }\end{array}$ & $\begin{array}{l}\text { Water } \\
(\mathrm{g})\end{array}$ & $\begin{array}{c}\text { Methyl cellulose } \\
(\mathrm{g})\end{array}$ & $\begin{array}{c}\mathrm{pH} \text { controller } \\
(\mathrm{g})\end{array}$ & $\begin{array}{c}\text { Fly ash } \\
\text { (g) }\end{array}$ & $\begin{array}{c}\text { Metakaolin } \\
(\mathrm{g})\end{array}$ & $\begin{array}{l}\text { Quartz } \\
(\mathrm{g})\end{array}$ & $\begin{array}{c}\text { Atomizing slag } \\
(\mathrm{g})\end{array}$ & $\begin{array}{l}\mathrm{OPC} \\
(\mathrm{g})\end{array}$ \\
\hline Plain & 6.5 & 38.5 & 0.5 & 0.1 & - & - & 54 & - & 100 \\
\hline F5M0 & 6.5 & 38.5 & 0.5 & 0.1 & 5 & - & 49 & - & 100 \\
\hline F10M0 & 6.5 & 38.5 & 0.5 & 0.1 & 10 & - & 44 & - & 100 \\
\hline F15M0 & 6.5 & 38.5 & 0.5 & 0.1 & 15 & - & 39 & - & 100 \\
\hline F10M1 & 6.5 & 38.5 & 0.5 & 0.1 & 10 & 1 & 43 & - & 100 \\
\hline F10M3 & 6.5 & 38.5 & 0.5 & 0.1 & 10 & 3 & 41 & - & 100 \\
\hline F10M5 & 6.5 & 38.5 & 0.5 & 0.1 & 10 & 5 & 39 & - & 100 \\
\hline P-AS10 & 6.5 & 38.5 & 0.5 & 0.1 & & & 31 & 10 & 100 \\
\hline P-AS20 & 6.5 & 38.5 & 0.5 & 0.1 & & & 21 & 20 & 100 \\
\hline FM-AS10 & 6.5 & 38.5 & 0.5 & 0.1 & 10 & 3 & 31 & 10 & 100 \\
\hline FM-AS20 & 6.5 & 38.5 & 0.5 & 0.1 & 10 & 3 & 21 & 20 & 100 \\
\hline \multicolumn{10}{|c|}{ Cement past test } \\
\hline Specimen & \multirow{2}{*}{\multicolumn{9}{|c|}{$\begin{array}{l}\text { RMAP } \\
\text { Cement mortar }\end{array}$}} \\
\hline & & & & & & & & & \\
\hline
\end{tabular}

TABLE 10: $\mathrm{pH}$ and viscosity of RMAP.

\begin{tabular}{lcccccccc}
\hline & & Plain & F5M0 & F10M0 & F15M0 & F10M1 & F10M3 & F10M5 \\
\hline \multirow{2}{*}{$\mathrm{pH}$} & Initial & 11 & 11.2 & 11 & 11.2 & 11 & 11 & 11 \\
& 6 months & 11 & 11.0 & 10.9 & 11.0 & 10.8 & 11 & 10.7 \\
\hline \multirow{2}{*}{ Viscosity (cP) } & Initial & 800 & 780 & 765 & 743 & 770 & 790 & 810 \\
& 6 months & 830 & 810 & 784 & 761 & 810 & 835 & 860 \\
\hline
\end{tabular}

increases owing to the ball bearing phenomenon caused by spherical particles.

3.2. Mechanical Properties after Mixing the Pozzolanic Admixture and Atomizing Slag. Figure 5 shows the adhesion tension graph for the cement mortar produced using RMAP. The adhesion tension at 3 days of age increased until the fly ash replacement ratio of $10 \%$ but decreased after $15 \%$. When metakaolin was used instead, the adhesion tension increased up to a $3 \%$ replacement ratio.

At 7 days of age, the adhesion tension showed a similar trend to that at 3 days of age until the fly ash replacement ratio of $10 \%$; however, in the case of metakaolin, the adhesion tension increased until the replacement ratio of $5 \%$. Furthermore, at 14 days of age, strength values showed an increasing trend similar to that in the case of the mortar of 7 days of age. In the case of compressive strength, the strength 


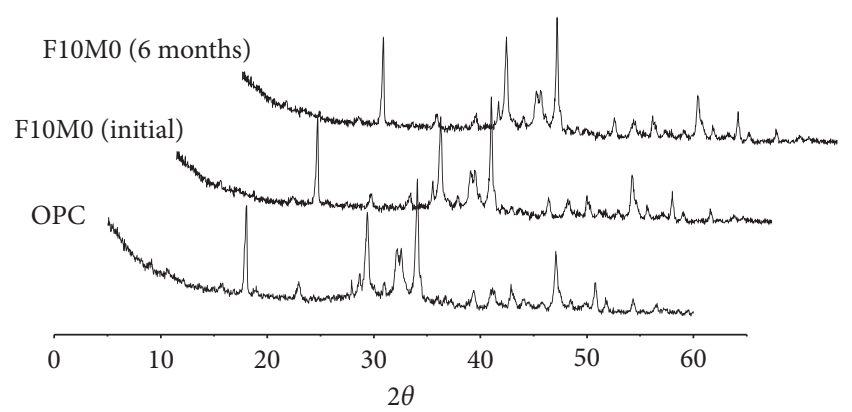

FIgURE 2: XRD graph for the semi premix paste after 3 days.

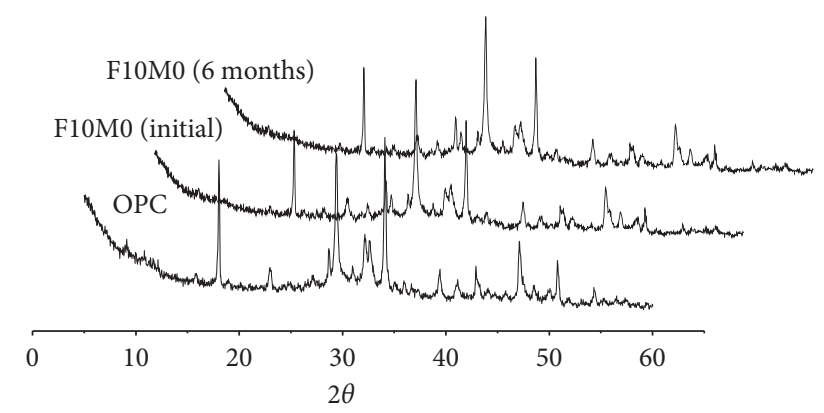

FIGURE 3: XRD graph for the semi premix paste after 28 days.

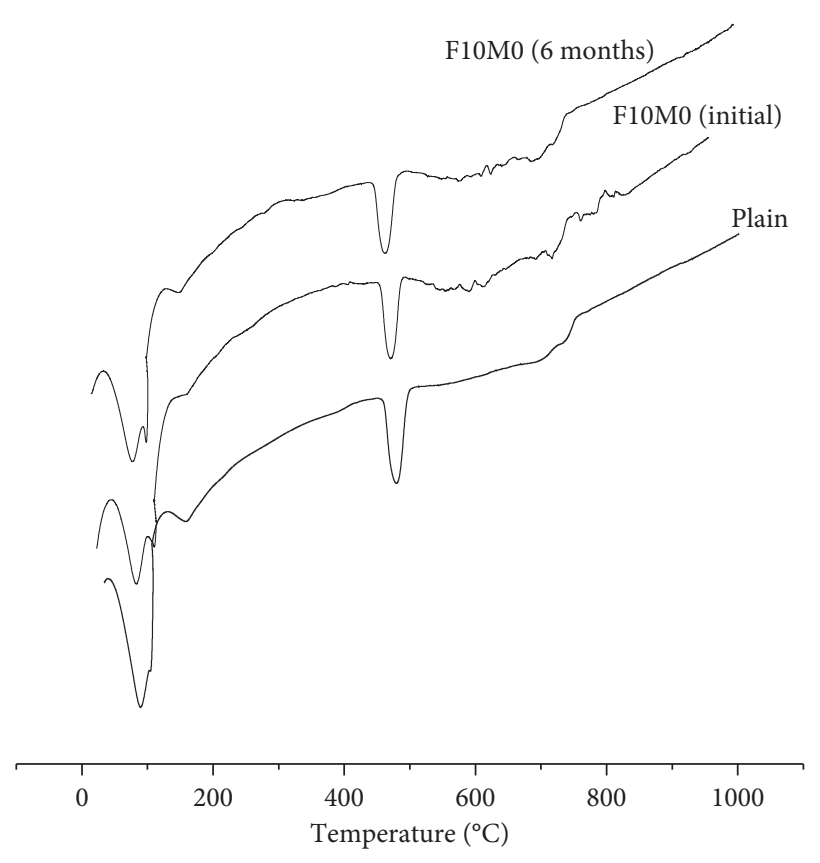

Figure 4: TG-DTA graph for RMAP with cement after 3 days.

increased as the replacement ratios of fly ash and metakaolin increased; in contrast, in the case of adhesion tension, the largest value was observed at $10 \%$ fly ash and 3\% metakaolin.

Furthermore, the compressive strength increased with increasing age as the internal voids are filled. However, the adhesion tension is realized owing to anchoring from the hardening of the cement paste that penetrates into the voids of the adhered surface. Anchoring is essential for the manifestation of adhesion tension; adhesion may deteriorate if the specimen is fractured owing to shrinking deformation due to dry shrinkage after the cement specimen hardens. Therefore, it is considered that a specimen with a high initial adhesion tension may show a decrease in anchoring failure due to dry shrinkage, thus showing a strength trend that is different from that of the compressive strength.

Figure 6 shows the graph for the compressive strength of the cement mortar produced using RMAP. The compressive strength of the specimen mixed with fly ash increased until the mixing ratio of $5 \%$ and decreased after that. In contrast, in the case of metakaolin, the compressive strength increased even at $1 \%$ mixing ratio and showed the highest value at 28 days of age when the mixing ratio was $5 \%$.

Figure 7 shows the graph for the flexural strength of the cement mortar produced using RMAP. At 3 days of age, the compressive strength of the specimen mixed with fly ash increased until a 5\% mixing ratio and decreased after that. At 28 days of age, however, the flexural strength increased until $10 \%$ mixing ratio. In contrast, when metakaolin was mixed, the flexural strength improved at 3 days of age; however, it was lower than that of the plain specimen. Nevertheless, at 28 days of age, the flexural strength was high in all mixtures of metakaolin.

3.3. Mechanical Properties of the RMAP Based on the Replacement Ratio of Atomizing Slag. Figure 8 shows the adhesion tension graph for cement mortar based on the replacement ratio of the atomizing slag. As the mixing ratio of the atomizing slag increased, the adhesion tension at 3 days of age was slightly higher than that of the specimen using quartz, and a similar trend was observed until 28 days of age. For specimens modified with fly ash and metakaolin, the adhesion tension at 3 days of age was higher by $0.1 \mathrm{~N} /$ $\mathrm{mm}^{2}$ than the unmodified specimen.

Figure 9 shows the compressive strength graph for the cement mortar based on the replacement ratio of the atomizing slag. As the mixing ratio of the atomizing slag increased, the specimen showed higher compressive strengths compared with the plain specimen at 3 and 28 days of age. However, the specimens modified with fly ash and metakaolin showed lower compressive strengths at 3 days of age but higher compressive strengths at 28 days of age. Because the atomizing slag is a spherical particle, it is considered that the strength is increased due to the improvement of the filling performance due to the increase of fluidity $[26,27]$.

Figure 10 shows the flexural strength graph for the cement mortar based on the replacement ratio of the atomizing slag. As the mixing ratio of the atomizing slag increased, the specimen showed higher flexural strengths compared with the plain specimen at 3 and 28 days of age. However, the specimens modified with fly ash and metakaolin showed lower flexural strengths at 3 days of age but higher compressive strengths at 28 days of age.

3.4. Coefficient of Water Absorption for RMAP Modified with the Admixture. Figures 11 and 12 show the graph for the 
TABle 11: Amount of $\mathrm{Ca}(\mathrm{OH})_{2}$ according to curing age.

\begin{tabular}{|c|c|c|c|c|}
\hline \multirow{3}{*}{ Specimen } & \multicolumn{4}{|c|}{ Amount of $\mathrm{Ca}(\mathrm{OH})_{2}$} \\
\hline & \multicolumn{2}{|r|}{3 days } & \multicolumn{2}{|r|}{28 days } \\
\hline & Absolute value (\%) & Equivalent to plain specimen (\%) & Absolute value (\%) & Equivalent to plain specimen (\%) \\
\hline Plain & -2.426 & 100 & -1.956 & 100 \\
\hline F10M0 (initial) & -1.768 & 72.87 & -1.508 & 77.10 \\
\hline F10M0 (6 months) & -1.81 & 74.60 & -1.592 & 81.39 \\
\hline F10M3 (initial) & -1.419 & 58.49 & -1.276 & 65.23 \\
\hline F10M3 (6 months) & -1.451 & 59.81 & -1.329 & 67.94 \\
\hline
\end{tabular}

TABLE 12: $\mathrm{pH}$ and viscosity of the RMAP.

\begin{tabular}{|c|c|c|c|c|c|c|}
\hline & & Plain & P-AS10 & P-AS20 & FM-AS10 & FM-AS20 \\
\hline Unit weight $(\mathrm{kg})$ & & 2105 & 2160 & 2210 & 2140 & 2190 \\
\hline \multirow{2}{*}{ Segregation } & Initial & Not detected & Not detected & Not detected & Not detected & Not detected \\
\hline & 6 months & Not detected & Detected & Detected & Not detected & Not detected \\
\hline \multirow{2}{*}{ Viscosity $(\mathrm{cP})$} & Initial & 10,000 & 9,200 & 8,700 & 11,200 & 11,600 \\
\hline & 6 months & 10,500 & 9,300 & 8,750 & 11,500 & 11,300 \\
\hline Flow $(\mathrm{mm})$ & & 160 & 165 & 170 & 170 & 175 \\
\hline
\end{tabular}

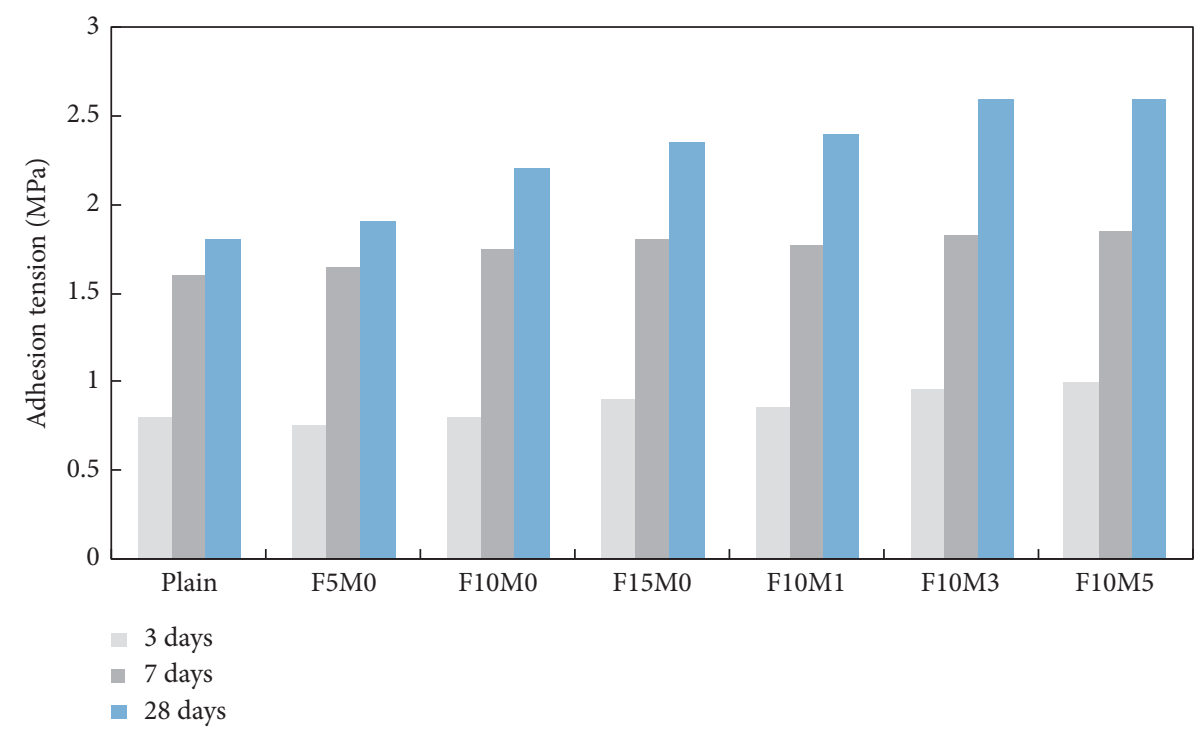

Figure 5: Adhesion tension for the cement mortar with RMAP.

coefficient of water absorption for the cement mortar modified with the admixture. In particular, the coefficient of water absorption showed a continuously decreasing trend until $15 \%$ fly ash. In contrast, when metakaolin was mixed, the coefficient of water absorption decreased as the mixing ratio increased. Furthermore, when the atomizing slag was mixed, the change in the coefficient of water absorption was not large.

3.5. MIP Analysis. Figure 13 shows the void characteristics of the specimen composed of RMAP and cement. The internal voids decreased after the pozzolanic admixture was added. Thus, the pozzolanic admixture is considered to be the cause of the decreasing coefficient of water absorption.

\section{Conclusions}

In our study, RMAP specimens were produced using industrial by-products; the characteristics of the obtained polymer-cement mortar produced using them were examined. Consequently, the following conclusions are obtained based on our study.

When the specimens were produced using pozzolanic admixtures in the RMAP, the properties immediately after mixing the RMAP were identical to those of the specimen after curing for six months; in addition, the properties of the RMAP with pozzolanic admixtures in the liquid state showed no deterioration.

In regard to the different pozzolanic admixtures used with the RMAP, using fly ash decreased the viscosity of the 


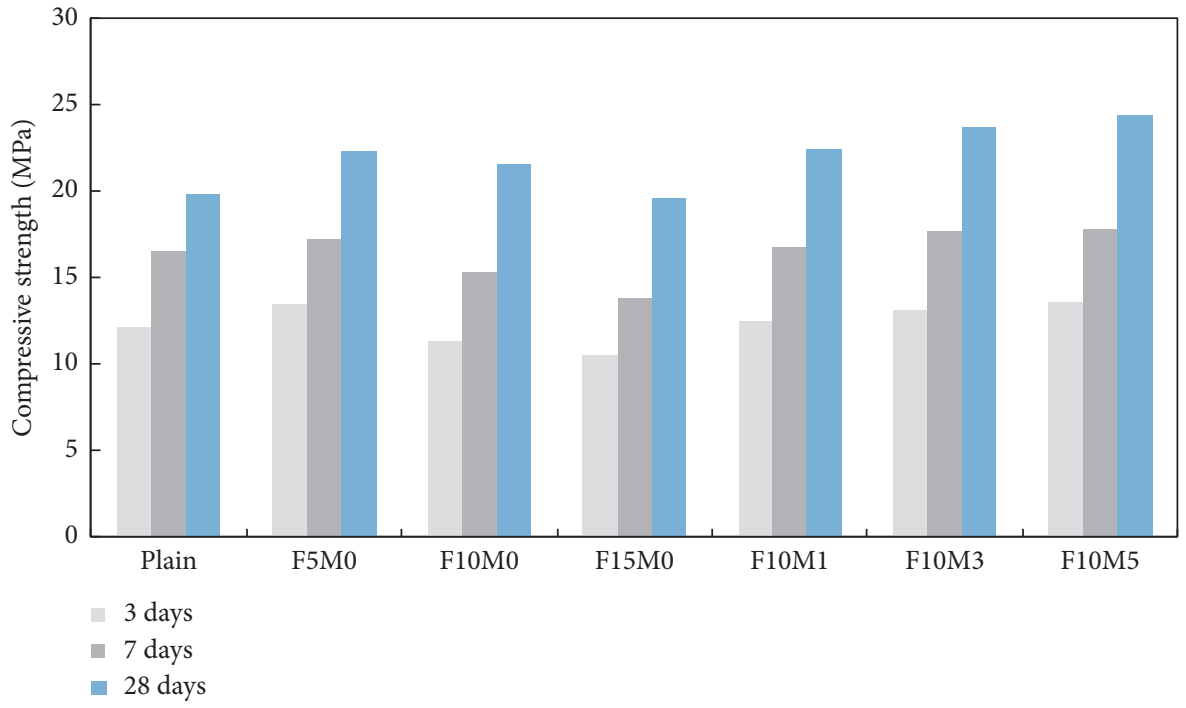

FIgURE 6: Compressive strength of the cement mortar with RMAP.

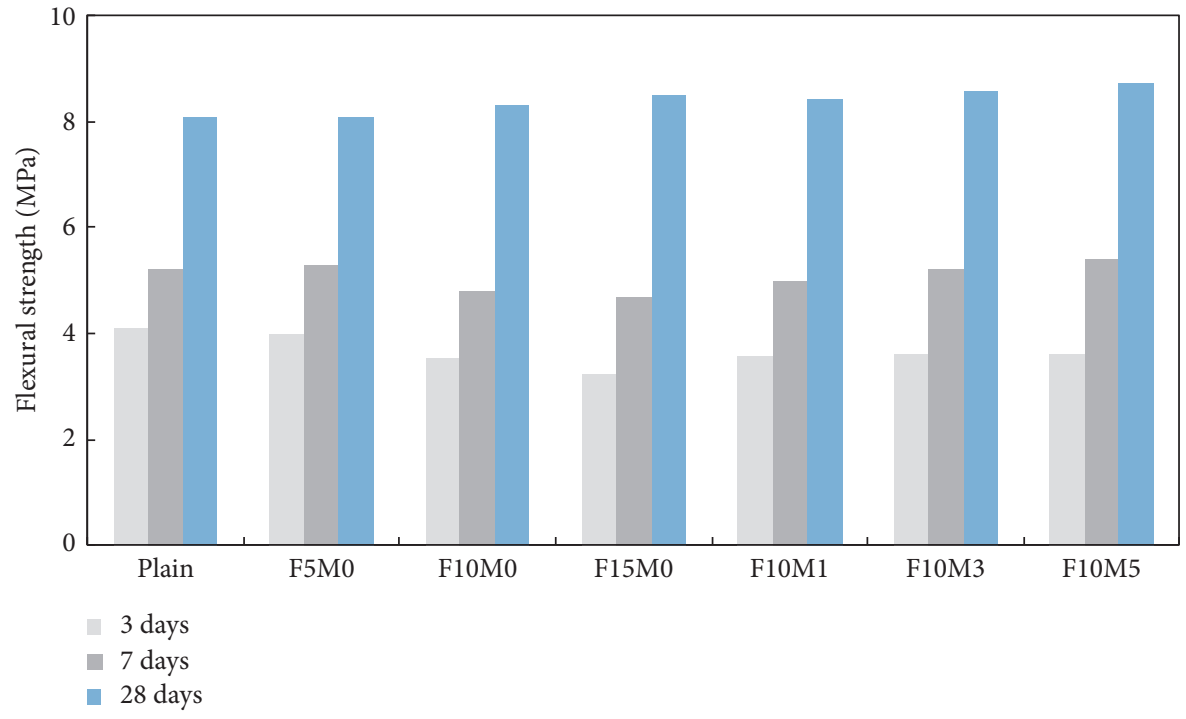

FIGURE 7: Flexural strength of the cement mortar with RMAP.

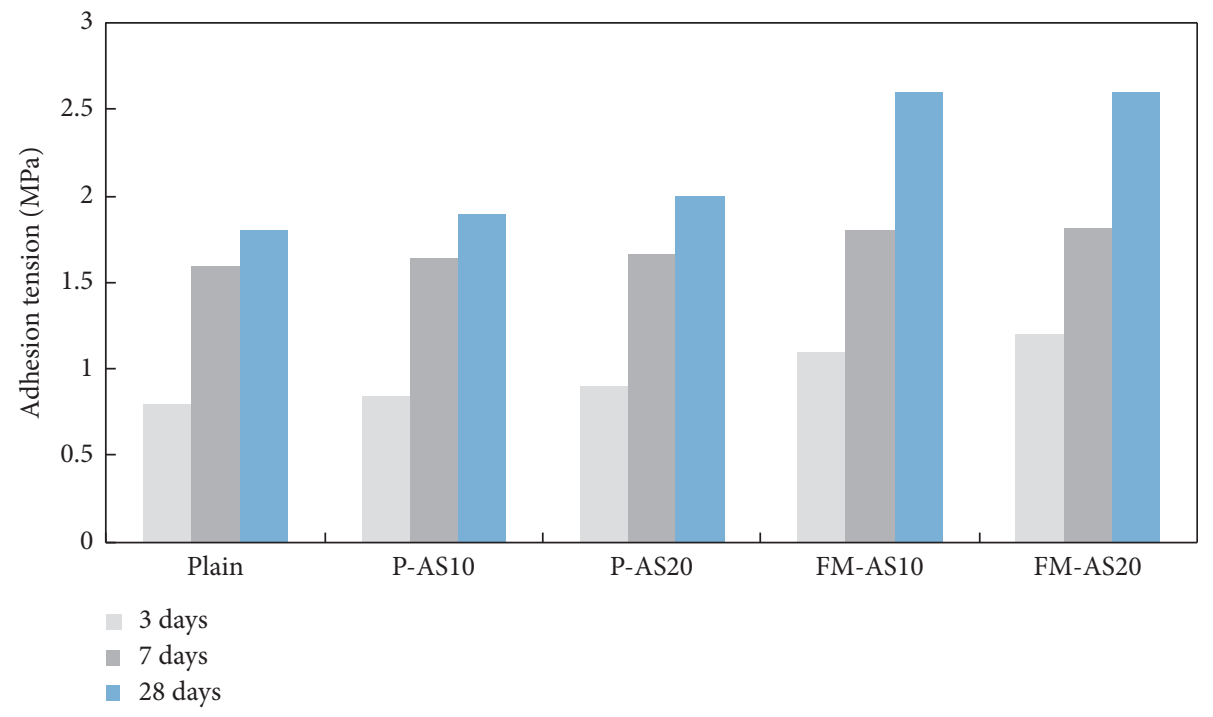

FIGURE 8: Adhesion tension for the cement mortar using atomizing slag-modified RMAP. 


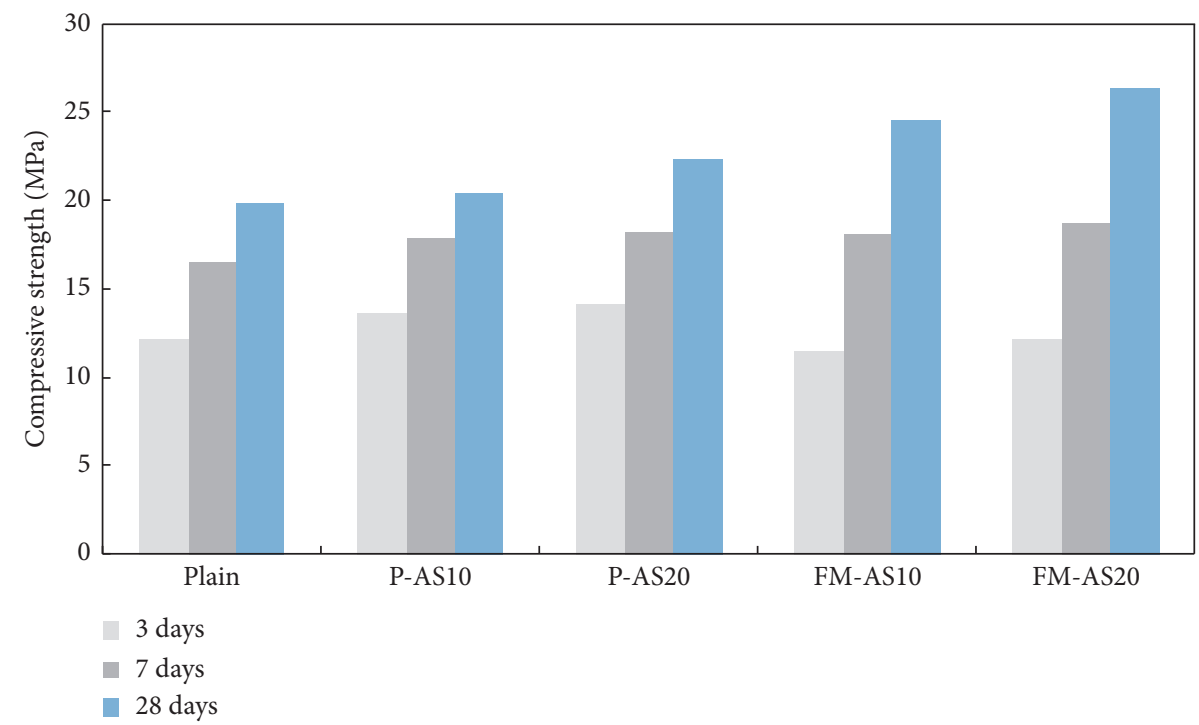

FIgURE 9: Compressive strength of cement mortar using atomizing slag-modified RMAP.

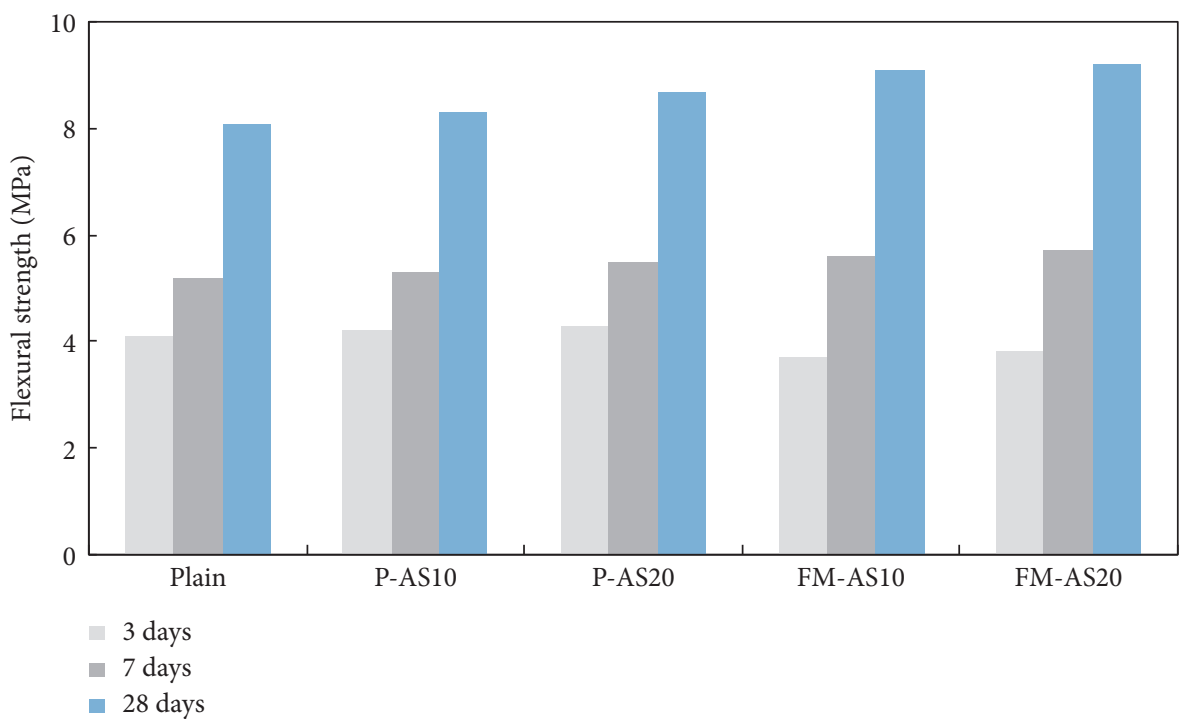

FIgURE 10: Flexural strength of cement mortar using atomizing slag-modified RMAP.

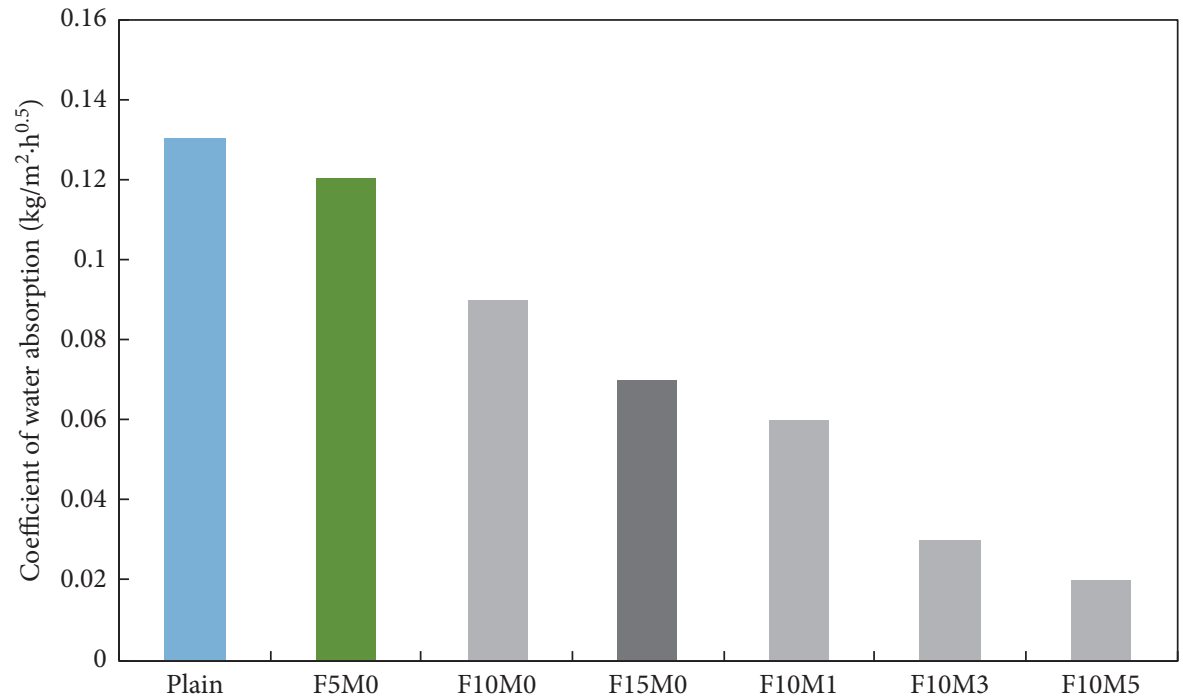

Figure 11: Coefficient of water absorption of the cement mortar with RMAP. 


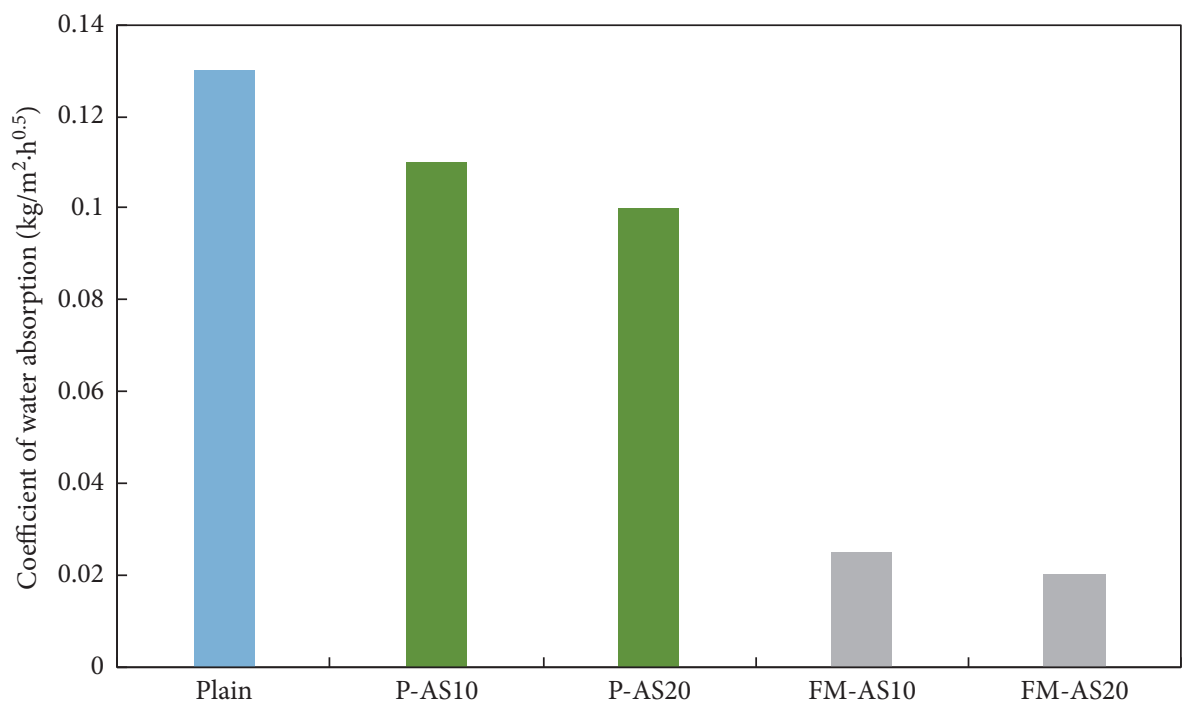

Figure 12: Coefficient of water absorption of the atomizing slag-modified RMAP.

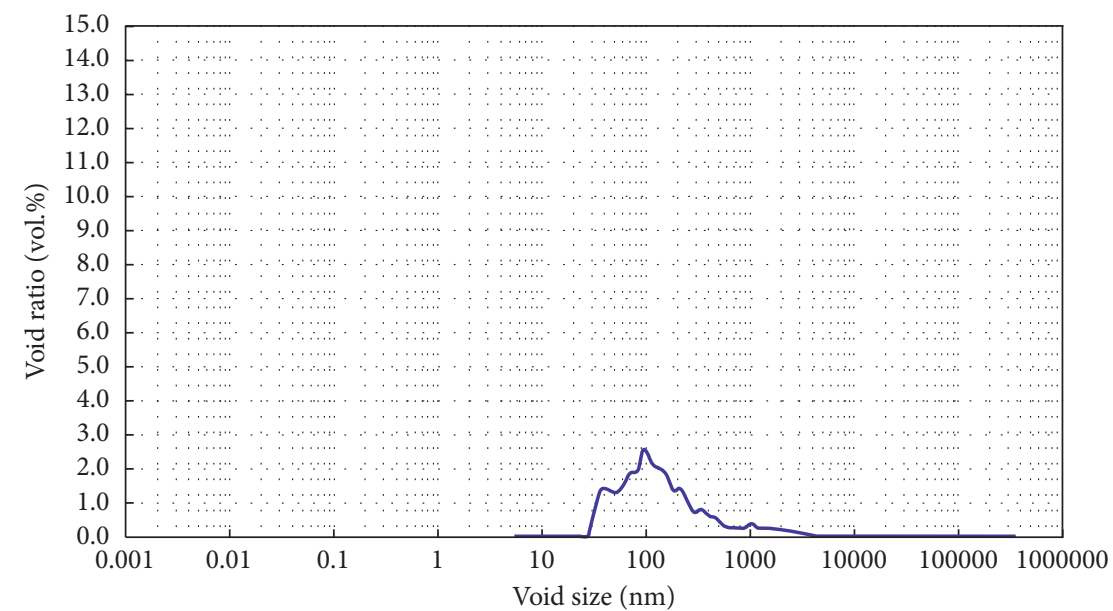

(a)

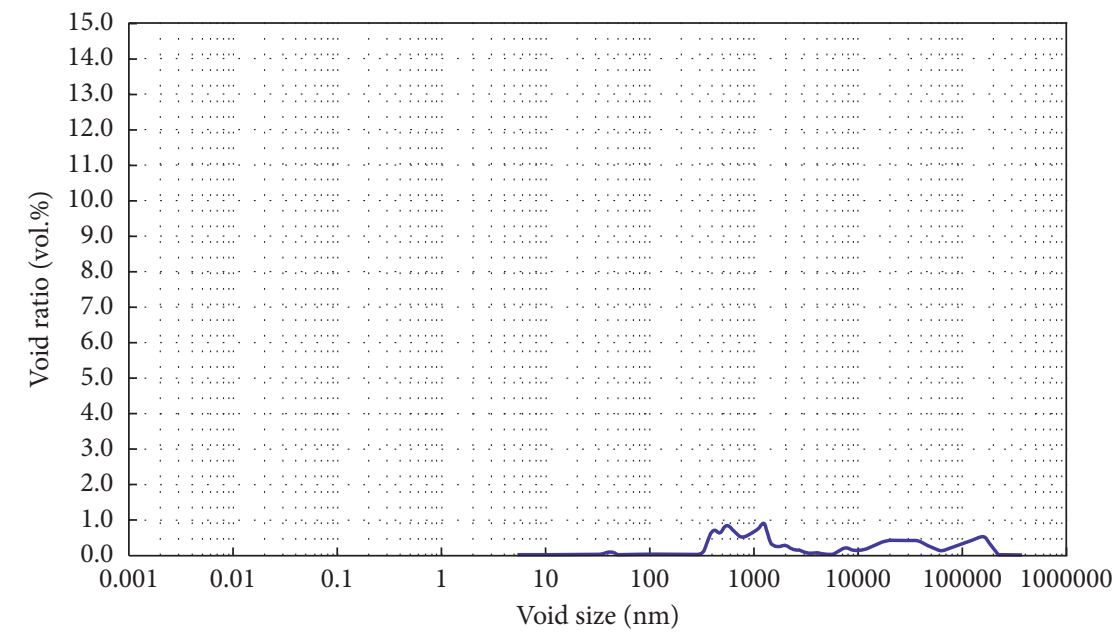

(b)

Figure 13: MIP graphs for RMAP with cement. (a) Plain. (b) F10M3. 
specimen, whereas metakaolin increased it. Thus, a product that has similar viscosity characteristics as the plain specimen could be produced by their combination.

The RMAP with the atomizing slag experienced segregation because of high specimen density six months after mixing. However, segregation could be suppressed by increasing the viscosity by the addition of fly ash and metakaolin. The RMAP with pozzolanic admixtures showed higher strengths than the plain specimen at every age considered in the study as well as in the case when a mixture of both fly ash and metakaolin was used. In the case of compressive and flexural strengths, the specimen with fly ash showed higher strengths than the plain specimen at early ages; however, the specimen using metakaolin showed higher strengths than the plain specimen even in the long term. It was also observed that the use of pozzolanic admixtures in the RMAP can ensure the stability of adhesion tension.

When the atomizing slag was used, the viscosity decreased and fluidity increased. The mixture with the atomizing slag showed strength-increasing effects for adhesion tension, flexural strength, and compressive strength. Thus, using pozzolanic admixtures could provide higher performance compared to plain specimens. The RMAP with pozzolanic admixtures showed a decrease in the coefficient of water absorption due to the effect of the filling of internal voids, which was confirmed using MIP analysis as well.

\section{Data Availability}

The XRD, TG-DTA, and MIP data used to support the findings of this study are available from the corresponding author on reasonable request. The other data used to support the findings of this study are included within the article.

\section{Conflicts of Interest}

The authors declare that there are no conflicts of interest regarding the publication of this paper.

\section{Acknowledgments}

This research was supported by grant number 18CTAPC130219-02 through the Korea Agency for Infrastructure Technology Advancement funded by the Ministry of Land, Infrastructure and Transport of the Korean government.

\section{References}

[1] J. L. Dentz, Evaluating Exterior Insulation and Finish Systems for Deep Energy Retrofits, New York State Research and Development Authority, Albany, NY, USA, 2017.

[2] European Organization for Technical Approvals (EOTA), ETAG 004: Guideline for European Technical Approval of External Thermal Insulation Composite Systems with Rendering, 2000.

[3] W. C. Brown, M. Lawton, and A. Lang, "Stucco-Clad walldrying experiment," BERC Report, Canada Mortgage and Housing Corporation, Ottawa, ON, Canada, Section 4, 1999.

[4] M. Bomberg, K. Kumaran, and K. Day, "Moisture management of EIFS walls- Part 1: the basis for evaluation," Journal of
Thermal Envelope and Building Science, vol. 23, pp. 78-94, 2016.

[5] European Organisation for Technical Approvals (EOTA), ETAG 004: Guideline for European Technical Approval of External Thermal Insulation Composite Systems with Rendering, Section 5.1.3, 2000.

[6] http://www.terraco-eifs.com/basecoats.

[7] http://www.dryvit.com/products/adhesivesbase-coats/primus/.

[8] http://www.parex.com/products.pl.

[9] C. Shi and R. L. Day, "Pozzolanic reaction in the presence of chemical activators: Part II-reaction products and mechanism," Cement and Concrete Research, vol. 30, pp. 607-613, 2000.

[10] P. T. Bui, Y. Ogawa, K. Nakarai, and K. Kawai, "A study on pozzolanic reaction of fly ash cement paste activated by an injection of alkali solution," Construction and Building $\mathrm{Ma}$ terials, vol. 94, pp. 28-34, 2015.

[11] N. Wang, H. Peng, X. Ling, J. Kang, and M. Xu, "Experimental investigation of slag particles of ligament mode disintegration in spinning disk atomizing," Energy Procedia, vol. 105, pp. 622-627, 2017.

[12] E. H. Hwang, C. H. Lee, and J. M. Kim, "Physical properties of polymer concrete composite using rapid-cooled steel slag (I)," Applied Chemistry for Engineering, vol. 23, pp. 210-216, 2012.

[13] D. G. Montgomery and G. Wang, "Instant-chilled steel slag aggregate in concrete (strength related properties)," Cement and Concrete Research, vol. 21, pp. 1083-1091, 1991.

[14] L. Wang, K. Uji, and A. Ueno, "Evaluation on reaction efficient of fly ash based on threshold value of replacement ratio," Cement Science and Concrete Technology, vol. 71, pp. 645-652, 2017.

[15] ASTM, ASTM D 1293-99, Standard Test Methods for $p H$ of Water, 1999.

[16] ASTM, ASTM D 1365-18, Standard Test Method for Determination of the Proportion of Phases in Portland Cement and Portland-Cement Clinker Using X-Ray Powder Diffraction Analysis, 2018.

[17] ASTM, ASTM D 3850-12, Standard Test Method for Rapid Thermal Degradation of Solid Electrical Insulating Materials By Thermogravimetric Method, 2012.

[18] ASTM, ASTM D 2196, Standard Test Methods for Rheological Properties of Non-Newtonian Materials by Rotational Viscometer, 2015.

[19] ASTM, ASTM C 1610, Standard Test Method for Static Segregation of Self-Consolidating Concrete Using Column Technique, 2017.

[20] ASTM, ASTM C 230/230M-14, Standard Specification for Flow Table for Use in Tests of Hydraulic Cement, 2014.

[21] ASTM, ASTM C 349 (Test Method for Compressive Strength of Hydraulic-Cement Mortars (Using Portions of Prisms Broken in Flexure)), 2014.

[22] ASTM, ASTM C 348-14, Standard Test Method for Flexural Strength of Hydraulic-Cement Mortars, 2014.

[23] ASTM, ASTM D 7234-12, Standard Test Method for Pull-Off Adhesion Strength of Coatings on Concrete Using Portable Pull-Off Adhesion Testers, 2012.

[24] ASTM, ASTM C 1794-15, Standard Test Methods for Determination of the Water Absorption Coefficient by Partial Immersion, 2015.

[25] ASTM, ASTM D 3850-12, Standard Test Method for Rapid Thermal Degradation of Solid Electrical Insulating Materials by Thermogravimetric Method (TGA), 2012. 
[26] H. Qasrawi, “Towards sustainable self-compacting concrete: effect of recycled slag coarse aggregate on the fresh properties of SCC," Advances in Civil Engineering, vol. 2018, Article ID 7450943, 9 pages, 2018.

[27] Y. Pan, Bond Strength of Concrete Patch Repairs, A Doctoral Thesis, Loughborough University, Loughborough, UK, 1995. 


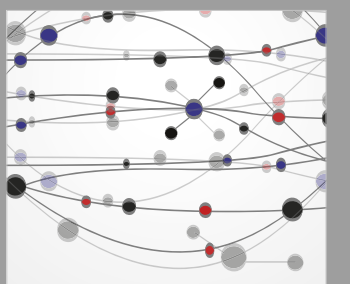

The Scientific World Journal
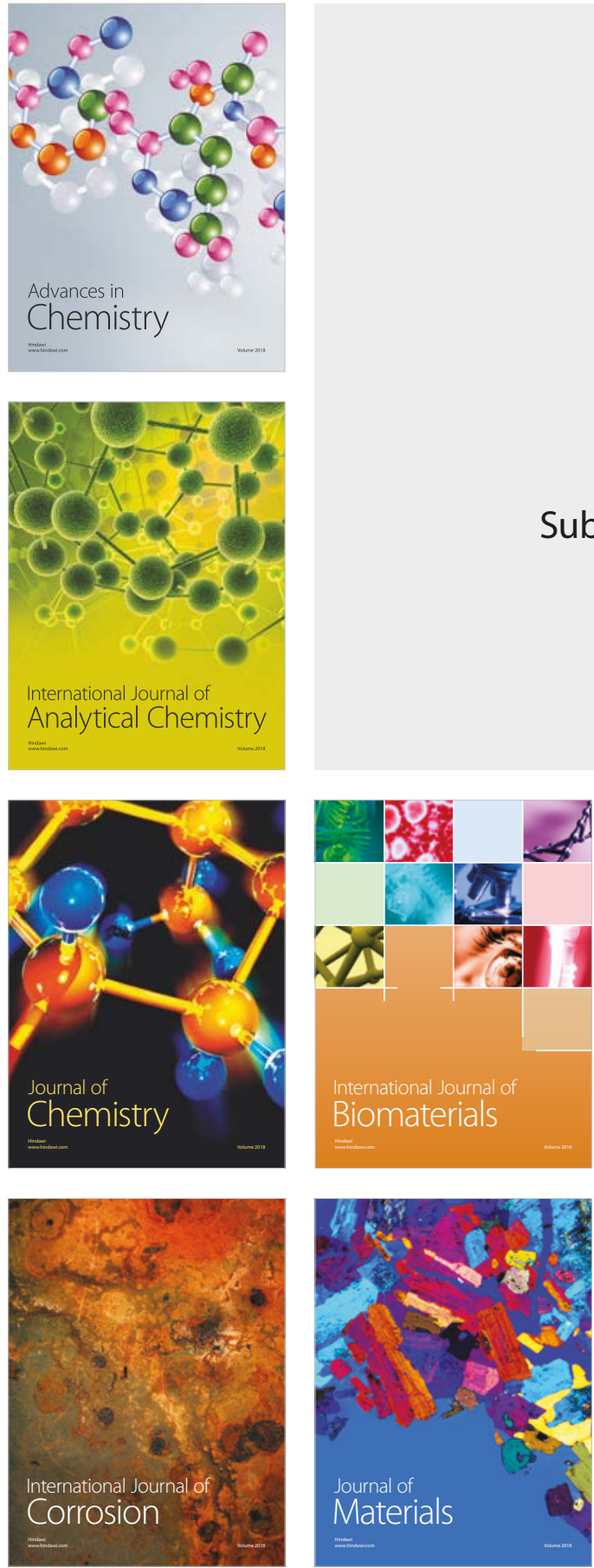

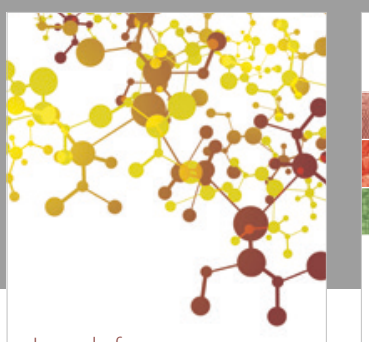

Journal of

Applied Chemistry
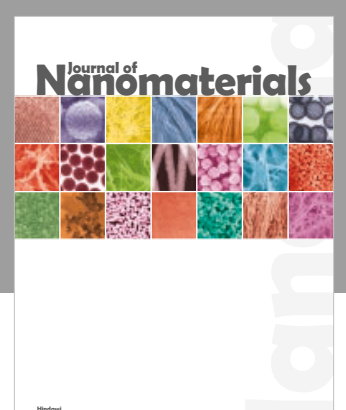

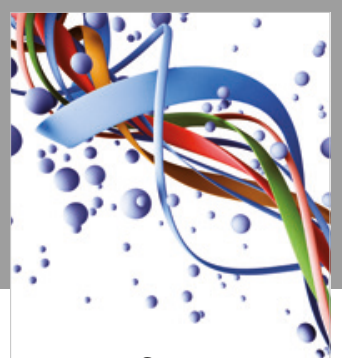

Scientifica

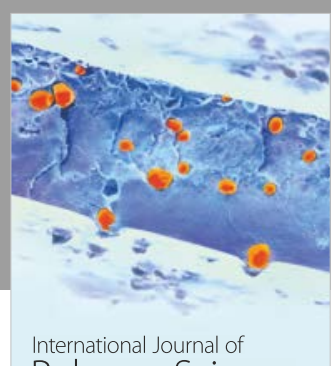

Polymer Science

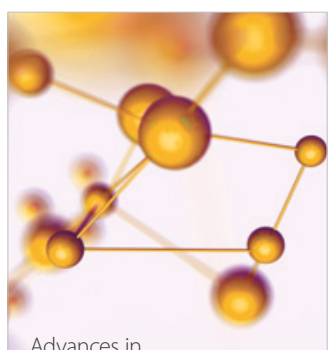

Physical Chemistry
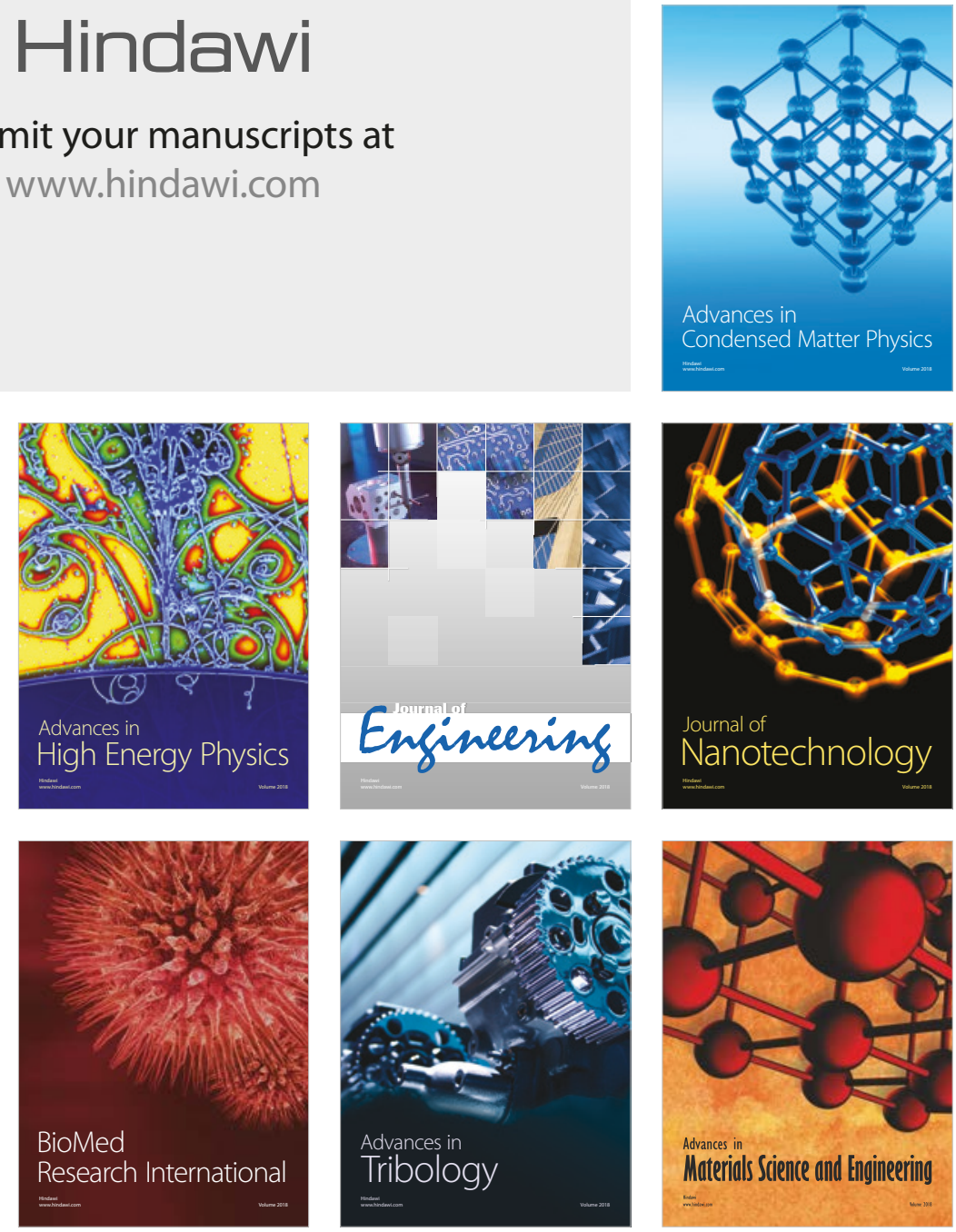